\title{
As narrativas e as pesquisas sobre formação de professores: apontamentos teórico- metodológicos sobre a produção das pesquisas
}

\author{
Narratives and research on teacher education: theoretical and methodological \\ notes on research production
}

\author{
Caio Corrêa Derossi ${ }^{1}$ \\ Karen Laíssa Marcílio Ferreira ${ }^{2}$
}

\begin{abstract}
RESUMO
O presente texto apresenta um balanço teórico-metodológico das pesquisas narrativas, com enfoque na temática de formação de professores. Assim, discutir-se-á as bases histórico-epistemológicas da construção do conhecimento nas ciências humanas, com a finalidade de localizar e de refletir sobre a metodologia das narrativas, inseridas no escopo das pesquisas (auto)biográficas em educação. Após a apresentação dos pressupostos teóricos deste tipo de pesquisa, seus principais autores e as obras com maior destaque, o texto reflete sobre categorias metodológicas que são constituintes da pesquisa, no que se refere aos elementos preconizados nas investigações, a postura do pesquisador e a forma a qual se concebe e se realiza a produção dos dados e dos resultados. Neste sentido, o sujeito tem protagonismo no cenário de construção das pesquisas, entendendo que os elementos de lembrança, de esquecimento, de seleção das memórias são partes das narrativas, que revelam não apenas singularidades, mas os momentos históricos, contextos político, social e econômico que compõem as distintas representações e imaginários sociais dos sujeitos.
\end{abstract}

Palavras-chave: metodologia das narrativas; formação de professores; pesquisa em educação.

\begin{abstract}
This text presents a theoretical-methodological balance of narrative research, focusing on the theme of teacher education. Thus, the historical-epistemological basis of the construction of knowledge in the human sciences will be discussed, with the purpose of locating and reflecting on the methodology of narratives, within the scope of (auto) biographical research in education. After presenting the theoretical assumptions of this type of research, its main authors and the most prominent works, the text reflects on the methodological categories that are constituents of the research, regarding the elements advocated in the investigations, the researcher's attitude and the form which the production of the data and the results are conceived and carried upon. In this sense, the subject has the protagonism in the scenario of research construction, understanding that the elements of remembering, forgetting, memory selection are the part of the narratives, which reveal not only singularities, but also historical moments, political, social and economic contexts that make up the different representations and the social imaginary of the subjects.
\end{abstract}

Keywords: narrative methodology; teacher training; research in education.

\footnotetext{
${ }^{1}$ Licenciado em História pela Universidade Federal de Viçosa. Mestrando no Programa de PósGraduação em Educação da mesma instituição. E-mail: derossi.caio@gmail.com.

${ }^{2}$ Licenciada em Pedagogia pela Faculdade Capixaba da Serra. Mestranda no Programa de PósGraduação em Educação na Universidade Federal de Viçosa. E-mail: karenkaispa @ gmail.com.
} 
Palavras iniciais: caminhos, sertões e veredas do texto

Com a virada discursiva ou linguística, denominada em inglês como linguist turn, nas Ciências Humanas, a partir da década de 1980, fez com que as narrativas tomassem centralidade no campo das pesquisas, como objeto e como metodologia, oportunizando, como aponta Bastos et al (2015), na emergência de questões, contextos e atuações muito próprias. Neste sentido, são os indivíduos que contam, recontam e significam suas histórias. Assim, a partir das trajetórias dos sujeitos, somos convidados a refletir outros tempos históricos, memórias, representações, imaginários e subjetividades criadas a partir das condições reveladoras de suas práticas e formações.

Portanto, acredita-se que as trajetórias nos informam sobre a atuação e a prática dos professores. Logo, Souza (2006, p. 101) afirma que “(...) a narrativa nos oferece um terreno de implicação e compreensão dos modos como se concebe o passado, o presente e, de forma singular, as dimensões experienciais da memória". Neste mesmo sentido, Josso (2004a; 2004b) afirma que as aprendizagens da docência estão relacionadas aos processos identitários e às suas narrativas.

Assim, o presente texto aspira oferecer uma visada teóricometodológica sobre o histórico das pesquisas narrativas, discutindo, a partir de uma perspectiva epistemológica, a construção do conhecimento nas pesquisas com este tipo de instrumen- to, com maior ênfase para o campo educacional. Em seguida, discute-se os aspectos metodológicos das pesquisas narrativas. Primeiramente, foram pensadas em termos teóricos sobre a incorporação de novos objetos e sujeitos nas pesquisas, no caso, as narrativas, as experiências e o protagonismo dos sujeitos. Posteriormente, na seção seguinte, aponta-se alguns caminhos para a reflexão e a análise das narrativas e caminhos, horizontes para a escrita dos trabalhos.

As duas últimas seções realizam de forma mais imbricada a contextualização das pesquisas narrativas com o campo de estudos de formação de professores e do desenvolvimento profissional da docência. Nessa direção, explicita-se a implicação com os sujeitos das pesquisas e os ganhos que tal aparelho metodológico lega e oferece aos estudos da temática formativa docente.

\section{Perspectivas histórico-metodológicas das pesquisas narrativas}

Segundo Nóvoa e Finger (2010), o método narrativo emerge no campo das Ciências Sociais fazendo uma contraposição ao modelo sociológico positivista. O positivismo é uma corrente filosófica e sociológica de pensamento, que surgiu na França no século XIX e se mantém em destaque no campo científico até as primeiras cinco décadas do século XX. Com Auguste Comte e John Stuart Mill como principais expoentes, a escola de pensamento postulava que o conhecimento científico deveria ser conside- 
rado como o único verdadeiro. Os sociólogos norte-americanos dos anos de 1920 e 1930 são os primeiros a utilizar o método narrativo, que, segundo Ferrarotti (1998), respondeu a uma necessidade de mudança de paradigmas nas Ciências Humanas, de novos elementos heurísticos para a metodologia nas Ciências Sociais e a emergência de áreas como a Antropologia e as pesquisas com o cotidiano. Essa nova perspectiva faz com que a escrita das histórias dos sujeitos "se [tornem] instrumento sociológico que parece poder vir a assegurar esta mediação do ato à estrutura, de uma história individual à história social" (FERRAROTTI, 1988, p.20).

Ferreira (2016) trata que a metodologia narrativa e biográfica se apresentou nos campos da história e da educação subvertendo o protagonismo dos sujeitos, em um movimento de retirada dos grandes personagens $\mathrm{e}$ acontecimentos, por personagens comuns e cotidianos, vencidos e silenciados, escondidos em uma interpretação hegemônica que só aparecem em uma leitura a contrapelo (BENJAMIN, 1985). Neste sentido, Souza (2007) retrata:

O resultado desse empreendimento é uma terminologia característica da história, pois, a partir desse momento, é possível agrupar os termos autobiografia, biografia, relato oral, depoimento oral, história de vida, história oral de vida e as narrativas de formação como desmembramentos da expressão polissêmica História Oral. Sendo que, nas pesquisas em educação, adota-se a história de vida, mais especificadamente o método autobiográfico e as narrativas de formação como fontes principais de pesquisa. (SOUZA, 2007, p. 62).
Nessa nova perspectiva, os quais os sujeitos, seus contextos e suas histórias estão na centralidade da pesquisa, Souza (2006) retrata uma nova ordem nas produções dos campos de história e de educação, sendo a última sentida nas áreas de história da educação, do currículo, das políticas educacionais, da cultura e das práticas nas instituições chegando até as temáticas da profissionalização docente.

Freitas e Ghedin (2015) retratam que, a partir da década de 1980, na Europa, ocorreu uma crescente de trabalhos nas perspectivas narrativa, biográfica e de história de vida que colocou no centro das discussões a figura do professor, a exemplo de trabalhos como $O$ professor é uma pessoa e $O$ método auto(biográfico) e a formação, de Ada Abraham (1984) e de Antonio Nóvoa e Matthias Finger (1988), respectivamente. Assim, marca-se o movimento de ouvir as vozes dos professores. (GOODSON, 1982).

Pineau (2006) fez uma pesquisa sobre as produções que utilizavam o método de história de vida e categorizou em três fases de sua escrita. A primeira fase é localizada nos anos de 1980, que marca o início das pesquisas com essa metodologia. A segunda, representando a consolidação do campo, percorre os anos de 1990. Os anos de 2000 é marcado pelo desenvolvimento das pesquisas. Segundo Pineau (2006), além dele, Franco Ferrarotti, Pierre Dominicé, Guy de Villers, Guy Bonvalot, Marie-Christine Josso e Bernadette Courtois, Matthias Finger e Antonio Nóvoa são considerados os pesquisadores pioneiros na área. 
Logo, de acordo com Freitas (2015), existe no Brasil uma tendência no acompanhamento dos aspectos teórico-metodológicos das pesquisas internacionais, assim, conforme nos aponta Souza (2006), os sujeitos tomam a centralidade das pesquisas, a partir dos temas de representações sociais da docência, os ciclos de vida e profissional, as narrativas do professorado, entre outros, que compunham as produções brasileiras.

\section{As narrativas como possibilidade metodológica para as pesquisas}

Ao longo das últimas décadas, a pesquisa narrativa vem ganhando maior destaque no campo das Ciências Humanas e Sociais, principalmente na área educacional, tecendo a teia das histórias dos sujeitos. Nesse sentido, Thompson (1992) trata que toda experiência humana é matéria-prima para a História, no caso, para uma nova História. Assim, Lima e Mioto (2007), defendendo o uso da pesquisa narrativa, afirmam que:

\footnotetext{
O uso do narrar- e, portanto, das narrativas- tem se constituído uma estratégia metodológica cada vez mais comum nas ciências sociais e humanas e tem extrapolado o campo da história, pois possibilita a compreensão de um universo construído no dia a dia a partir de práticas aprendidas com gerações anteriores, pouco capitadas nos documentos e por meio da aplicação de questionários. (LIMA; MIOTO, 2007, p.38)
}

Assim, a narrativa é um instrumento importante que assegura as vozes que tratam de si e sobre si, escolhe o que deve ser rememorado e transmitido, bem como as as reflexões que são propostas. Assim, Freitas e Ghedin (2015, p.119), sobre as narrativas, retratam que: "tal categoria integra diversas pesquisas ou projetos de formação, através das vozes dos atores sobre uma vida singular, sobre vidas plurais ou sobre vidas profissionais, no particular e no geral, por meio da tomada da palavra como estatuto da singularidade, da subjetividade e dos contextos dos sujeitos".

Conforme pesquisam Connelly e Clandinin (2011), principais referências para as produções e para os pesquisadores norte-americanos, a pesquisa narrativa representa um objeto de estudo e uma metodologia. Assim, quando se pensam a formação e a profissão docente, as narrativas dão corpo aos conhecimentos, as práticas, os contextos e os sujeitos que se intercruzaram pelas vidas destes professores. Logo, para Connelly e Clandinin (2011), é através das narrativas que as experiências são representadas e oferecem as histórias de vida protagonismo nas pesquisas.

As lembranças e as memórias são constituídas em uma face de reflexão pessoal, própria e coletiva, em função dos sujeitos e dos contextos que se intercruzam os indivíduos. Assim, Souza (2006) reforça essa perspectiva de formação das lembranças, a partir das experiências e dos pensamentos dos sujeitos, quando afirma que "a memória é escrita num tempo, um tempo que permite deslocamento sobre as experiências. Tempo e memória que possibilitam conexões com as 
lembranças e os esquecimentos de si, dos lugares, das pessoas, da família, da escola e das dimensões existenciais do sujeito narrador" (SOUZA, 2006, p.64).

Assim, segundo Souza (2006), as narrativas coadunam as teias social e individual dos sujeitos, o que concerne em uma metodologia potente para as pesquisas. Assim, Souza (2006) ainda dispõe que:

A crescente utilização da pesquisa narrativa em educação busca evidenciar e aprofundar representações sobre as experiências educativas e educacionais dos sujeitos, bem como potencializa entender diferentes mecanismos e processos históricos relativos à educação em diferentes tempos [...] permitem adentrar num campo subjetivo e concreto, através do texto narrativo, das representações de professores sobre a identidade profissional, os ciclos de vida e, por fim busca entender os sujeitos, os sentidos e as situações do contexto escolar. (SOUZA, 2006, p.136)

Portanto, Larrosa (1994 apud FERREIRA, 2016, p.25) afirma que: "Por meio dessa exposição é que esse sujeito dá forma a como vê, sente e pensa em relação à sua vida, o que fará trazer à tona aquilo que, de alguma forma, traduz-se como traços subjetivos de sua existência". Bueno et al. (2006), sobre as pesquisas e as metodologias narrativas, (auto)biográfica e histórias de vida, no Brasil, associamse a criação do grupo de pesquisas da Faculdade de Educação da Universidade de São Paulo denominado Docência, Memória e Gênero, que, em 1994, tomaram as produções da Universidade de Genebra, na Suíça e de autores como Marie-Christine Josso,
Pierre Dominicé e Gaston Pineau, como exemplos norteadores. É no bojo dessa instituição também que as perspectivas (auto)biográficas são utilizadas para pensar a (auto) formação dos professores. O Congresso Internacional de Pesquisas (Auto)biográfico (CIPA), realizado a partir de 2004, é outro momento marcante para o desenvolvimento dessas pesquisas no país. O CIPA é um evento bianual que já se encontra em sua sétima edição.

Souza $(2006 ; 2010)$ alerta que existe uma miríade de denominações para pesquisas do tipo biográfica, a depender da área do conhecimento, como no caso da História Oral e de suas variações para a ciência histórica. Mas, conforme o autor, para o campo da educação, pesquisa (auto)biográfica, narrativas e história de vida são as mais utilizadas. Nesse sentido, o método narrativo é uma fortuita lente para análise das experiências, das vivências e de outros constructos subjetivos dos professores.

Passegi (2011) afirma que o movimento dialético de retratar sobre o que nos toca, nos afeta e nos constitui é campo frutífero para as pesquisas educacionais, uma vez que as versões novas, novas impressões e novas experiências que emergem, fortalecem o lastro do viver, que também é narrar. Sobre as inter-relações entre viver e narrar, Abrahão (2006), no texto de Freitas e Ghedin (2015), afirma:

\footnotetext{
A narração se apresenta no contexto de formação, segundo Ricoeur (1995, 2007 apud ABRAHÃO, 2006), com uma natureza tridimensional, em que passado, presente e futuro se imbricam, no sentido de que o caráter temporal da experiência do sujeito, tanto na ordem pes-
} 
soal quanto social, é articulado pela narrativa. A natureza temporal tridimensional da narrativa consiste em que esta promove a rememoração do passado com olhos e questionamentos do presente e permite prospectar o futuro como possibilidade de transformação e autotransformação do próprio sujeito. Por esta razão, o próprio discurso narrativo não procura necessariamente obedecer a uma lógica linear sequencial, porque a vida não tem essa natureza. (ABRAHÃO, 2006, p.103).

Assim, as narrativas não são apenas uma descrição densa do que aconteceu, mas memórias e lembranças, portanto, recortes considerados significativos, dos narradores, que, conforme Cunha e Chaigar (2009), ressignificam no momento da narração e possibilitam espaço para os imaginários, representações e novas significações dos interlocutores. Destarte, Freitas e Ghedin (2015) tratam que este processo das narrativas prenhe das representações e dos imaginários, o desenvolvimento da linguagem é central para a organização das ideias e da própria narrativa, frente ao interlocutor, as imagens e as passagens da sua vida.

\section{As narrativas e os seus métodos: particularidades implicadas com os sujeitos}

As narrativas e outros materiais caracterizados como (auto)biográficos, fontes das investigações, podem ser construídos de forma primária, a partir de entrevistas entre o pesquisador e o sujeito, bem como de fundo secundário, que já foram produzidos, como: cartas, correspondências, fotografias, relatos, depoimentos, reportagens entre outros. Os métodos baseados no Positivismo, no Estruturalismo, teorias de grande relevo e predomínio antes da revisão paradigmática supracitada, que oportunizou a emergência das narrativas, tinha predileção as fontes, sobretudo aos documentos já produzidos, pois imaginava-se que eles continham uma verdade sobre o retratado e que a linguagem era objetiva, sem marcas intencionais. Entretanto, o método narrativo convida que o pesquisador se volte às histórias primárias dos sujeitos. Nesse sentido, Ferrarotti (2010, p.43) retrata que:

\footnotetext{
Devemos voltar a trazer ao coração do método biográfico os materiais primários e sua subjetividade explosiva. Não é só a riqueza do material biográfico primário que nos interessa, mas também, sobretudo, a sua pregnância subjetiva no quadro de uma comunicação interpessoal complexa e recíproca entre o narrador e o observador.
}

Assim, sobre as relações conflituosas entre um subjetivismo presente nas narrativas e um tipo de objetividade exigido em um entendimento sobre pesquisa científica, Ferrarotti (2010) explica que, no método (auto)biográfico, as narrativas são próprias da práxis humana, conceito estudado por Karl Marx, que revela a essência das relações humanas, suas apropriações, suas relações, que irão impactar a constituição do eu, bem como do processo de significação do mundo.

Ferrarotti (2010) também cita o filósofo existencialista francês JeanPaul Sartre, para dizer que a burguesia forja uma identidade universal singular do ser humano. Assim, todo sujeito é 
singular inserido em uma lógica sóciohistórica, revelando que se pode conhecer a estrutura social a partir das particularidades da práxis individual. Portanto, é legítimo a leitura da sociedade através das narrativas particulares. Entretanto, cabe ressaltar que tais histórias não são apenas um conjunto de experiências, mas, sim, o sujeito posicionado em uma teia de micro/macro relações sociais. Logo, Ferrarotti (2010, p. 45) considera que o "menor dos monólogos não deixa de ser uma tentativa de comunicação e implica o fantasma de um interlocutor". Nessa direção, o autor esclarece que esse sujeito, que pode até se pretender invisível, na verdade transparece uma realidade, quando indaga, procura pelas narrativas. Então, Ferrarotti (2010, p.46) retrata que:

As narrativas biográficas de que nos servimos não são monólogos ditos perante um observador reduzido à tarefa de suporte humano de um gravador. Toda entrevista biográfica é uma interação social completa, um sistema de papéis, de expectativas, de injunções de normas e de valores implícitos e, por vezes, até de sanções. Toda entrevista biográfica esconde tensões, conflitos e hierarquias de poder; apela pelo carisma e para o poder social das instituições científicas relativamente às classes subalternas, desencadeando as reações espontâneas de defesa.

Mesmo perante às condições colocadas pelo método, as narrativas constituem uma possibilidade fortuita para o estudo da formação de professores. Isso, pois, a partir das singularidades contidas nas histórias de vida, podemos entender os contextos sociais.

\section{As histórias de vida inscritas nos estudos sobre a profissão docente}

Nóvoa (1992) trata que, quando se pesquisa e se reflete sobre a formação docente e a profissão de professor, existe uma indissociabilidade entre as atmosferas pessoal e profissional daqueles sujeitos. Assim, as narrativas contribuem para divulgar histórias clivadas de aspectos individuais e sociais, coletivos. Assim, Nóvoa (1995) identifica que o trabalho com a análise das narrativas é um marco em relação ao tipo de pesquisa desenvolvido até então, com base no paradigma da racionalidade técnica, reduzindo o papel e a formação do professor, entendido como personificação de habilidades e competências, separando as dimensões pessoal e profissional, corroborando para a crise na profissão docente. Então, com a virada teóricometodológica, os modos de vida, as situações e as práticas dos professores contribuem para o entendimento da profissão docente. Logo, para DeloryMomberger (2008, p. 22), “a escrita biográfica não dissocia jamais a relação consigo mesmo da relação com o outro". Neste sentido, quando se reflete a própria vida, abre-se horizontes para compreender as narrativas vivenciadas por outros. Então, DeloryMomberger (2008, p.22) destaca que: "A narrativa do outro é um dos lugares onde experimentamos nossa própria construção biográfica”.

Assim, Roldão (1995) retrata que as narrativas e os distintos cotidianos e práticas culturais tem sido utilizados em pesquisas educacionais em 
várias partes do mundo, como forma de reconhecimento das potencialidades e dos desafios das narrativas, representações e imaginários nas relações de ensino-aprendizagem dos professores. Nesse sentido, Egan (1986) dispõe que a partir de contextos micro, relacionados as práticas cotidianas, podem contribuir para ações e resoluções em escala macro, possibilitando ressignificar as experiências. Logo, Reis (2008) enfatiza o papel das narrativas, como um campo de conhecimento que oferece elementos metodológicos para pesquisar os professores e sua formação. Assim, Clandinin e Connelly (2011, p.20) escrevem que: "A narrativa é inerente a ação humana e, portanto, deve ser estudada dentro dos seus contextos social e educativo. Desta forma, atribuem grande valor ao contexto em que se conta a narrativa, às razões que levam o narrador a contá-la e ao tipo de audiência a que se destina". Neste mesmo sentido, Souza escreve que:

A arte de lembrar remete o sujeito a observar-se numa dimensão genealógica, como um processo de recuperação do eu, e a memória narrativa marca um olhar sobre si em diferentes tempos e espaços, os quais articulam-se com as lembranças e as possibilidades de narrar experiências. O tempo é memória, o tempo instala-se nas vivências circunscritas em momentos; o tempo é o situar-se no passado e no presente. (SOUZA, 2006, p.102).

Em consonância com Oliveira e Reis (2003), as práticas narrativas com fundo de memória oferecem pistas de suas práticas e formações, bem como os desejos de tais sujeitos, em meio a uma sociedade de transformação contínuas, de relação entre espaçotempo encurtadas, de esquecimento, de excesso de informações, estabelecendo a confluência entre os vários fatores na constituição pessoal e da profissão. Assim, Reis (2008), sobre as narrativas direcionadas ao desenvolvimento e a formação de professores, afirma que:

\begin{abstract}
A construção de narrativas e a sua leitura, análise e discussão, em contextos de formação inicial e contínua, encerram potencialidades no desenvolvimento pessoal e profissional dos professores. Os professores, quando contam histórias sobre algum acontecimento do seu percurso profissional, fazem algo mais do que registrar esse acontecimento; acabam por alterar formas de pensar e de agir, sentir motivação para modificar as suas práticas e manter uma atitude crítica e reflexiva sobre o seu desenvolvimento profissional. Através da construção de narrativas os professores reconstroem as suas próprias experiências de ensino e aprendizagem e os seus percursos de formação. (REIS, 2008, p.20)
\end{abstract}

Nesse sentido, as narrativas oferecem possibilidade de investigar os processos de ensino e de aprendizagem dos professores e de seus desenvolvimentos profissionais, uma vez que, como afirma Reis (2008), o movimento narrativo propõe uma aproximação entre o que é relatado e os interlocutores, já que elementos como a sensibilização, a identificação são mobilizados. Portanto, as histórias de professores com mais tempo de serviço podem ser potencializadoras para a reflexão e inspiração de pares e de outros profissionais. Assim, Reis 
(2008) coloca que o processo de reconstituição das histórias dos professores pode propor mudanças na construção dos conhecimentos pedagógicos e profissionais. Logo, as narrativas compõem um movimento dialético, entre a própria história, outras vozes, dissonantes e abafadas pela escrita da história, com intenções e desejos vários, propondo até o melhor conhecimento do próprio pesquisador, que realiza a pesquisa. Assim, o movimento de investigação é como um espelho que reflete imagens, que tratam das faces múltiplas desses professores. Freitas e Galvão (2007) encaminham na mesma direção de Reis (2008), quando afirmam que:

A construção da metodologia de investigação se constitui em uma narrativa na medida em que a recolha de dados são as escritas autobiográficas sobre os percursos singulares que foram sendo reconstruídas por nós, investigadoras, no entrecruzamento de nossas histórias de professoras e formadoras de professores e pesquisadores. A análise ressignifica e reinterpreta os olhares que temos de nós mesmas, pondo em evidência outras emoções e razoes das quais antes não tínhamos percebido. (FREITAS; GALVÃO, 2007, p.219)

Assim, Moita (1995) e Freitas e Galvão (2007) trataram da integração dos aspectos pessoais e profissionais no desenvolvimento da docência, ao ponto que em uma via se revisita o passado, outro caminho, concomitante, potencializa e ressignifica as próprias histórias, alterando seus percursos ainda em movimento, em continuidade. Logo, Freitas e Galvão (2007) apon- tam que as narrativas revelam, para além de uma face pessoal, memórias coletivas, contextos e fatos considerados objetivos que compõem as subjetividades, o que impactará nas análises e considerações sobre as narrativas.

Como supracitado, o movimento de redefinição e consolidação da pesquisa narrativa dos anos de 1990, segundo Melo (2013), sofrerá também uma influência das políticas educacionais, uma vez que esta década é marcada pela atuação dos organismos internacionais nas políticas sociais, entre elas a educação, bem como no avanço das ideias privatistas e de descentralização do financiamento do Estado para a pasta educacional. Assim, a Lei de Diretrizes e Bases da Educação Nacional (LDB), como apontam Melo (2013) e Freitas (2002), com a ideia de profissionais da educação, ao invés de professores, representando uma diferenciação e um avanço na ideia de profissionalização do professorado, em voga desde os anos de 1970, com os inícios das discussões, e nos anos de 1980, com o debate da docência frente a profissão, a formação e a missão, o dom e o sacerdócio.

Destarte, conforme Miranda (2008), as implicações dessa nova concepção sobre a profissão docente irrompem com uma noção que a formação deve privilegiar uma dimensão prática em detrimento dos conhecimentos teóricos, dos específicos da profissão visando a uma constituição reflexiva, autônoma e permanente. Logo, com base do contexto exposto, observa-se uma mudança relacionada a profissão docente e a seus processos formativos. 


\section{A formação de professores a partir do aparato metodológico das narra- tivas}

A pesquisa sobre formação de professores precisa considerar o processo de constituição dos sujeitos bem como as perspectivas seguidas pelos pesquisadores, sua orientação teórica. Nesse sentido, Josso afirma que:

A palavra formação apresenta uma dificuldade semântica, pois designa tanto a atividade no seu desenvolvimento temporal, como o respectivo resultado. Designando o nosso objeto de investigação pelo próprio conceito de processo de formação, indicávamos mais claramente que nos interessávamos pela compreensão da atividade. Todavia, mantémse uma ambiguidade, à medida que o conceito utilizado não permite distinguir a ação de formar (do ponto de vista do formador, da pedagogia utilizada e de quem aprende) da ação de formar-se. (JOSSO, 2010, p.61)

No que se refere à formação de professores, as narrativas são consideradas como resultado parcial, selecionado e refletido sobre as histórias vividas e não um sequencial de fatos. Assim, as interrogações são pontos de partida e de chegada para outras histórias que compõem o exercício da pesquisa, evidenciando estreita relação entre pesquisador e pesquisado. Nesse sentido, para além de uma contribuição ao campo de pesquisa educacional, as narrativas colocam o professor em protagonismo, sua formação e a investigação sobre tais aspectos. Portanto, Esteban (2010, p.153) afirma que:
[...] desde vários anos atrás, houve uma progressiva recuperação do método autobiográfico na Antropologia, na Sociologia, na Psicologia Social e na Pedagogia. O ser humano recupera o protagonismo, em relação às excessivas abstrações e à desumanização do cientificismo positivista. Pujadas (1992); Santamarina e Marinas (1995) afirmam que esse fenômeno traz uma característica ou sintoma de uma época que podemos chamar de sintoma biográfico.

As pesquisas que utilizam dos métodos (auto)biográficos e narrativos estão bastantes difundidos em vários campos das Ciências Humanas, contribuindo para análise de diversas questões a partir das próprias narrativas. Clandinin e Connelly (2011) entendem como uma relação sinonímica os léxicos narrativa e história. Assim, sugerem que os termos podem ser utilizados de forma indiferente, uma vez que a preocupação central é o desenvolvimento, a formação e a pesquisa sobre/para/por professores.

As narrativas, em forma oral ou escrita, são instrumentos culturais, inerentes ao ser humano e utilizados por muito tempo, como retratou Houston (2010). Tais narrativas carregam consigo as aprendizagens perpassadas por gerações e guardam conflitos, diferentes imaginários, suas resoluções, bem como as sensações que as histórias geram entre os sujeitos, os pesquisadores e os interlocutores. Os sentimentos, as afetações geradas mobilizam identidades múltiplas, no movimento de aproximação e estranhamento da reflexão. As narrativas dos pró- 
prios professores podem fomentar nestes docentes uma reflexão, que, independentemente do período da carreira e do desenvolvimento profissional da docência, podem gerar mudanças nas práticas, representações e imaginários sobre a docência (REIS, 2012). Assim, com o movimento narrativo, os sujeitos recontam suas histórias, de modo a reconstruir e ressignificar sua atuação. Cabe destacar também que o fato de os professores narrarem para outros professores e pelo fato de, muitas vezes, serem os professores os principais leitores, impactam em como narram e em como são recebidas as histórias. Assim, as narrativas podem ser usadas, para além da pesquisa, como um instrumento formativo.

\section{Para não concluir: as narrativas como instrumento de pesquisa em educação}

Freitas e Galvão (2007) afirmam que as narrativas possibilitam entender, ao menos em parte, como ocorrem os processos de constituição profissional dos pesquisados e até mesmo do pesquisador. Segundo as autoras:

Olhar para o passado pode ajudarnos a encontrar explicação para significados nas ações que temos hoje como pessoas que foram construindo um percurso pessoal e profissional rico de cruzamentos com os outros e a dar sentido ao nosso posicionamento como professoras e formadoras de professores. As nossas intenções são acadêmicas, mais do que pessoais, embora saibamos que a pessoa e o profissional se interligam e se expressam de um modo completo e integrado (MOITA, 1995). O recurso à narrativa autobiográfica inscreve-se na ideia de que, ao narrarmos episódios com significado, os analisaremos de uma forma contextualizada, tentando que essa análise ponha em evidência emoções, experiências ou pequenos fatos marcantes, dos quais antes não nos tínhamos apercebido. (FREITAS; GALVÃO, 2007, p.2)

Assim, as narrativas possibilitam a reflexão sobre a profissionalização dos docentes e carregam com si uma forma metalinguística de proposição da pesquisa, já que a metodologia de narrativas são as próprias narrativas contadas e histórias reescritas pelo pesquisador. Bolívar (2002) apontou que uma das principais contribuições da pesquisa narrativa para educação foi poder ouvir, fazer com que as vozes emergissem dos personagens que figuravam nas pesquisas, sem ser considerados os professores. Assim, para além das complexas redes de sentimentos mobilizados, Bolívar (2002, p. 3) destaca também que:

La investigación biográfica y narrativa en educación, en lugar del modo de cientificidad dominante en la modernidad, reclama otros criterios, superadora del contraste establecido entre objetividad y subjetividad, para basarse en las evidencias originarias del mundo de la vida. Como modo de conocimiento, el relato capta la riqueza y detalles de los significados en los asuntos humanos (motivaciones, sentimientos, deseos o propósitos) que no pueden ser expresados en definiciones, enunciados factuales o proposiciones abstractas, como hace el razonamiento lógico formal. 
O uso de narrativas então possibilita refletir sobre os significados das idiossincrasias apresentadas pelos sujeitos. Destarte, viabilizando o diálogo na construção de conhecimentos, não tendo apenas a interpretação do pesquisador, mas as vozes diretas dos sujeitos, fomentando e sendo potente instrumento para o estudo sobre formação de professores. 


\section{Referências}

ABRAHAM, A. $L^{\prime}$ Enseignant est une personne. Paris, Les Édition ESF, 1984.

ABRAHÃO. M. H. M. B. As narrativas de si ressignificadas pelo emprefo do método autobiográfico. In: SOUZA, Elizeu Clementino de; ABRAHÃO, Maria Helena Menna Barreto (Org.). Tempos, narrativas e ficções: a invenção de si. Porto Algre: EDIPUCRS; Salvador: EDUNEB, 2006. p. 149-170.

BASTOS, Liliana Cabral. Contando estórias em contextos espontâneos e institucionais- uma introdução ao estudo da narrativa. Calidoscópio. 3/2:74-87. 2005.

BENJAMIN, Walter. O narrador. Considerações sobre a obra de Nikolai Leskov. In: __ Magia e técnica, arte e política: ensaios sobre literatura e história da cultura. Trad. Sérgio Paulo Rouanet. São Paulo: Brasiliense, 1985. p. 197-221.

BUENO, Belmira O; CHAMLIAN, Helena Coharik; SOUSA, Cynthia Pereira de; CATANI, Denice Barbara. Histórias de vida e autobiografias na formação de professores e profissão docente (Brasil, 1985-2003). Educação e Pesquisa, São Paulo, vol. 32, núm. 2, maio/ago. 2006, p. 385-410.

BOLÍVAR, A. ¿De nobis ipsis silemus? Epistemología de la investigación biográfico-narrativa. Revista Electrónica de Investigación Educativa (REDIE), vol. 4 2002. Disponível em: <http://redie.ens.uabc.mx/vol 4 n.1/contenido-bolivar.html>.

CERTEAU, Michel de. A operação historiográfica. In: A escrita da

História. Rio de Janeiro: Forense Universitária, 1999. p. 65-109.

CLANDININ, D. J; CONNELY, F. M. Pesquisa Narrativa: experiência e história em pesquisa qualitativa. Uberlândia: EDUFU, 2011.

CUNHA, M. I.; CHAIGAR, V. A. M. A dimensão da escrita e da memória na formação reflexiva de professores: dois estudos em diálogo. In: FERREIRA, M. O. V.; FISCHER, B. T. D.; PERES, L. M. V. (Org.). Memórias docentes: abordagens teórico-metodológicas e experiências de investigação. São Leopoldo: Oikos; Brasília: Leber Livros, 2009. p. 119-140.

DELORY-MOMBERGER, C. Biografia e educação: figuras do indivíduo projeto. Trad. Maria Conceição Passegi, João Gomes da Silva Neto e Luis Passegi. Natal: Ed. UFRN; São Paulo: Paulus, 2008.

EGAN, K. O uso da narrativa como técnica de ensino. Lisboa: Publicações Dom Quixote, 1986. 
ESTEBAN, M. P. S. Pesquisa qualitativa em Educação: fundamentos e tradições. Porto Alegre: AMGH, 2010.

FERRAROTTI, Franco. Sobre a autonomia do método biográfico. In: NÓVOA, António; FINGER, M. (Orgs.). O método (auto)biográfico e a formação. Lisboa: Ministério da Saúde. Departamento de Recursos Humanos da Saúde/Centro de Formação e Aperfeiçoamento Profissional, 1988. p. 17-34.

FERREIRA, Thalita R. Experiências (auto)formativas na narração da história de vida de duas professoras: caminhos do ser-fazer docente. 2016. 201f. Dissertação (Mestrado em Educação) - Departamento de Ciências da Educação, Universidade Federal de São João Del-Rei, São João Del-Rei/MG, 2016.

FREITAS, D.; GALVÃO, C. O uso de narrativas autobiográficas no desenvolvimento profissional de professores. Ciências \& Cognição, 2007; v. 12, p. 219-233.

FREITAS, Helena Costa Lopes de. Formação de professores no Brasil: 10 anos de embates entre projetos de formação. Educação e Sociedade, Campinas, vol. 23, n. 80, set. 2002, p. 136-167.

FREITAS, L. M.; GHEDIN, E. L. Narrativas de formação: origens, significados e usos na pesquisa-formação de professores. Revista Contemporânea de Educação. v. 10, n. 19, jan./jun. 2015, p. 111-131.

HOUSTON, Nancy. A espécie fabuladora: um breve estudo sobre a humanidade. Porto Alegre: L\&PM, 2010.

JOSSO. M. C. Experiência de vida e formação. Tradução de José Cláudio e Júlia Ferreira. São Paulo: Cortez, 2004a.

Notas sobre narrativa y identidade (a modo de presentación). In: ABRAHÃO, M. H. M. B. (Org.). A aventura (auto)biográfica: teoria e empiria. Porto Alegre: EdiPUCRS, 2004b. p.12-13.

JOSSO, M. C. Da formação do sujeito ao sujeito da formação. In: NÓVOA, António; FINGER, M. (Org.). O método (auto) biográfico e a formação. Natal, RN: EDUFRN; São Paulo: Paulus, 2010.

LIMA, Telma Cristiane Sasso de; \& MIOTO, Regina Célia Tamaso. Procedimentos metodológicos na construção do conhecimento científico: a pesquisa bibliográfica. Revista Katálysis, 10 (Edição Especial), 2007, p. 37-45. 
MELO, Raquel S. M. de M. Por um projeto de EJA para Divinópolis: Memórias de professores e formação em esferas (também) políticas. 2013. 165f. Dissertação (Mestrado em Educação) - Instituto de Ciências Humanas e Sociais, Universidade Federal de Ouro Preto, Mariana/MG, 2013.

MIRANDA, Jovenal dos Reis. O currículo da formação incial de professores que atuam na Educação de Jovens e Adultos: do concebido ao vivido. 2008. 143f. Dissertação (Mestrado em Educação) - Faculdade de Educação, Universidade de Brasília, Brasília/DF, 2008.

MOITA, M.C. Percursos de Formação e de Trans-formação. Em: Nóvoa, A. Vidas de Professores. Porto: Porto Editor, p. 111-132, 1995.

NÓVOA, A. (Org.) Vidas de Professores. Porto: Porto Editora, 1992.

NÓVOA, A. Os professores e as histórias da sua vida. In: (Org.) ___ Vida de Professores. Porto: Porto Editora, 1995.

NÓVOA, A.; FINGER, M. (Org.). O método (auto)biográfico e a formação. São Paulo, SP: Paulus, 2010.

OLIVEIRA, S. S.; REIS, S. M. Tempos de Narrar... Tempos de rememorar. In: Elizeu Clementino Souza; Maria da Conceição Passeggi; Paula Perin Vicentini. (Org.). Pesquisa (Auto) biográfica: trajetórias de formação e profissionalização. 1ed. $\mathrm{Cu}$ ritiba - PR: CRV, v. 1, 2013, p. 71-88.

PASSEGI, Maria da Conceição; SOUZA, Elizeu Clementino; VICENTI, Paula Perin. Entre a vida e a formação: pesquisa (auto) biográfica, docência e profissionalização. Educação em Revista, Belo Horizonte/ MG, v. 27, n. 01, 2011, p. 369-386.

PINEAU, G. As histórias de vida em formação: gênese de uma corrente de pesquisaação-formação existencial. Educação e Pesquisa, São Paulo, v. 32, n. 2, maio/ago. 2006, p. 329-343.

REIS, Pedro R. d. As narrativas na formação de professores e na investigação em educação. Nuances: estudos sobre a educação. Pres. Prudente, SP, ano XIV v. 15 n 16. 2010.

REIS, P. G. R. El potencial educativo e investigativo de las narrativas. In: NURIA, C. REIS, P. G. R. Narrativas de profesores: reflexiones en torno al desarrollo personal y profesional. Andalucía: Universidade Internacional de Andalucía, 2012, p. 21-30. 
ROLDÃO, M. do Céu. As histórias em educação: A função mediática da narrativa. Ensinus, v. 3, p. 25-28, 1995.

SOUZA, E. C. O conhecimento de si: estágio e narrativas de formação de professores. Rio de Janeiro: DP\&A: Salvador: UNEB, 2006.

SOUZA, E. C. (Auto) biografia, histórias de vida e práticas de formação. In: NASCIMENTO, A. D.; HETKOWSKI, T. M. (org.). Memória e formação de professores [online], Salvador: EDUFBA, 2007. Disponível em: http://books.scielo .org/id/f5jk5/pdf/nascimento-9788523209186-04.pdf.

THOMPSON, Paul. A voz do passado: História Oral. Tradução de: Lólio Lourenço de Oliveira. Rio de Janeiro: Paz e Terra, 1992.

$O(s)$ autor(es) se responsabiliza $(m)$ pelo conteúdo e opiniões expressos no presente artigo, além disso declara(m) que a pesquisa é original.

Recebido em 08/03/2020

Aprovado em 12/06/2020 